\title{
Diffusive Convection under Rapidly Varying Conditions
}

\author{
Lars Umlauf, Peter L. Holtermann, Christiane A. Gillner, and Ralf D. Prien \\ Leibniz Institute for Baltic Sea Research, Warnemuende, Germany \\ LuCAS Merckelbach AND JeFFrey R. CARPENTER \\ Institute of Coastal Research, Helmholtz-Zentrum Geesthacht, Geesthacht, Germany
}

(Manuscript received 1 February 2018, in final form 24 May 2018)

\begin{abstract}
In most observations of diffusive convection in the ocean and in lakes, the characteristic diffusive staircases evolve over long time scales under quasi-stationary background conditions. In the Baltic Sea, however, diffusive staircases develop inside the flanks of intermittent intrusions that induce strong inverse temperature gradients over a vertical range of a few meters, varying on time scales of hours to days. Here, results are discussed from an extensive field campaign conducted in summer 2016 in the southern Baltic Sea, including temperature microstructure data from ocean gliders and an autonomous profiling platform. We find conditions favorable for diffusive instability in the vicinity of warm and cold intrusions with density ratios as small as $R_{\rho}=1.3$. The staircases evolving under these conditions are characterized by a small number of steps (typically $1-4$ ) with order $0.1-1-\mathrm{m}$ thickness, temperature differences exceeding $1 \mathrm{~K}$ across individual diffusive interfaces, and exceptionally large diffusive heat fluxes of order $10 \mathrm{~W} \mathrm{~m}^{-2}$. The standard heat flux parameterization of Kelley agrees within a factor of 2 with the directly observed interfacial heat fluxes, except for large fluxes at low $R_{\rho}$, which are strongly overestimated. The glider surveys reveal a surprisingly small lateral coherency of order $100 \mathrm{~m}$ of the staircase patterns, and a spreading of the diffusively unstable intrusions across isopycnals.
\end{abstract}

\section{Introduction}

Double diffusion is a turbulent convection process causing mixing of heat and salt in oceans and lakes. In the diffusive (or semiconvection) regime of double diffusion, an unstable temperature stratification, with temperature increasing with depth, is compensated by a stably stratified salinity profile. The conditions for doublediffusive instability are usually quantified with the help of the density ratio

$$
R_{\rho}=\frac{\beta \Delta S_{\mathrm{A}}}{\alpha \Delta \Theta},
$$

where $\Delta \Theta$ and $\Delta S_{\mathrm{A}}$ are the differences in Conservative Temperature and Absolute Salinity, respectively, across a representative depth interval, and $\alpha$ and $\beta$ are the corresponding thermal expansion and haline contraction coefficients (IOC et al. 2010). For a statically

Corresponding author: Lars Umlauf, lars.umlauf@iowarnemuende.de stable stratification $\left(R_{\rho}>1\right)$, double diffusion is able to drive convection through a release of the potential energy in the temperature profile by the different rates of molecular diffusion of temperature and salinity. This often results in the formation of layered diffusive staircases, with thin stably stratified interfaces separating actively convecting mixed layers (Radko 2013). In the ocean, such diffusive staircases are typically found for $1<R_{\rho}<10$ (Kelley et al. 2003).

In the overwhelming majority of observational studies in aquatic systems, diffusive convection is found to be a slow and low-energy mixing process. This is typified by diffusive oceanic staircases in the Arctic thermocline, with heat fluxes of $O(0.1) \mathrm{W} \mathrm{m}^{-2}$ (Timmermans et al. 2008; Guthrie et al. 2015; Shibley et al. 2017), and by limnic staircases such as those in Lakes Kivu and Powell, with heat fluxes of $O(0.01-0.1) \mathrm{W} \mathrm{m}^{-2}$ (Sommer et al. 2013b; Scheifele et al. 2014). Associated with these relatively small heat fluxes are slow time scales over which the staircases are thought to evolve, as well as the development of staircases that display little intrinsic lateral variability (Timmermans et al. 2008; Radko et al. 2014), 
unless that variability is imposed by destructive external processes such as shear or internal wave-driven mixing (Timmermans et al. 2003; Rippeth et al. 2015; Guthrie et al. 2017).

This has commonly led to the approximation of many staircase processes as one-dimensional, with rapid variation in the vertical, and only weak temporal and horizontal variability. The one-dimensional description has been successful in capturing important staircase features, such as formation mechanisms (Radko 2003; Radko et al. 2014) and vertical fluxes (Kelley 1990; Flanagan et al. 2013; Sommer et al. 2014; Hieronymus and Carpenter 2016). An extreme example of this horizontal homogeneity was found by Timmermans et al. (2008) in the Canada basin in the Arctic Ocean, where the diffusive staircase layers were coherent over hundreds of kilometers. Radko et al. (2014) interpreted this staircase coherency as the result of layer merging events reaching an equilibrium with the relatively steady background conditions in the Canada basin. Other observations from both lakes and oceans indicate possible scales of horizontal coherency as small as several hundreds of meters [as observed in Lake Kivu by Schmid et al. (2010)]. In the present study, we will describe observations from the Baltic Sea, where diffusive staircases evolve rapidly in time (on the order of days), exhibit little lateral coherency $(<100 \mathrm{~m})$, and generate exceptionally large heat fluxes up to $O(10) \mathrm{W} \mathrm{m}^{-2}$.

Because of its unique stratification and small internal mixing rates, the Baltic Sea (Fig. 1) constitutes an ideal natural laboratory for the investigation of doublediffusive processes. Stratification is determined by a long-term balance between freshwater runoff and intermittently occurring inflows of dense and salty North Sea waters, generating a strong, stable, and persistent vertical salinity gradient that usually dominates vertical stratification in the region below the seasonal thermocline (Feistel et al. 2008). Near-inertial waves have been shown to trigger shear instabilities in the stratified interior region (van der Lee and Umlauf 2011; Holtermann et al. 2017) but the resulting mixing rates were found to be small, and generally too small to explain the observed modifications of deep-water properties. The current belief, supported by a tracer release experiment and direct turbulence measurements in the bottom boundary layer, is that basin-scale deep-water mixing is dominated by boundary mixing processes (Holtermann et al. 2012; Lappe and Umlauf 2016).

However, as the sporadically intruding North Sea waters are often associated with significant temperature anomalies, it has long been speculated that diffusive instabilities could be a relevant mixing process in the vicinity of these intrusions. Based on $R_{\rho}$ estimated from

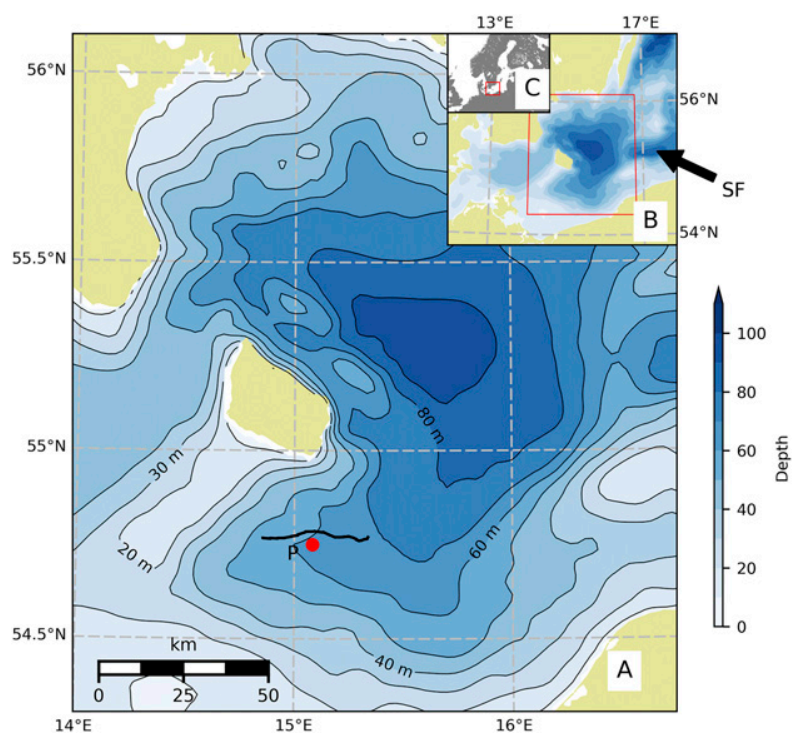

FIG. 1. (a) Map of study area with the mooring position P marked by a red dot, and the glider transect by a black line. (b),(c) Overview maps with the study area marked by a red rectangle (the black arrow indicates the location of the Stolpe Furrow).

densely spaced CTD measurements in the central Baltic Sea, Wieczorek et al. (2008) showed that the upper flanks of warm intrusions, triggered by a large-scale inflow event, are particularly susceptible for diffusive convection. The opposite case (cold waters intruding into a warm environment) was investigated by Kuzmina et al. (2005), who found density ratios indicative of diffusive convection at the lower flanks of the intrusions. None of these studies, however, was able to identify the thermohaline staircase structures that are generally considered as conclusive evidence for active diffusive convection. Only a recent investigation of mixing in the central Baltic Sea during a major inflow event (Holtermann et al. 2017) found direct evidence for the presence of diffusive staircases in high-resolution temperature profiles, however, without providing a detailed analysis.

Here, we use the unique conditions in the Baltic Sea to demonstrate that diffusive convection can lead to large heat fluxes in rapidly varying conditions in both time and space. This is done through the use of an extensive dataset including temperature microstructure measurements from both ocean gliders and an autonomous profiling platform.

\section{Study site and methods}

\section{a. Study site}

Our study area is located in the Bornholm basin in the southern part of the Baltic Sea (Fig. 1). With a lateral scale of $O(100) \mathrm{km}$ and a depth of approximately $95 \mathrm{~m}$, 
the Bornholm basin forms one of the largest subbasins of the Baltic Sea. Vertical stratification is dominated by a seasonal thermocline and a permanent halocline at $50-70 \mathrm{~m}$ depth that is maintained by sporadic intrusions of saline bottom waters from the neighboring Arkona basin via the Bornholm Channel. Local latitude and stratification correspond to an inertial period of $T_{f}=$ $14.56 \mathrm{~h}$ and a mode- 1 Rossby radius of $5-10 \mathrm{~km}$. As tides are virtually negligible, wind-generated near-inertial waves largely determine the dynamics of the basin, with most of the kinetic energy variability explained by the lowest two vertical modes (van der Lee and Umlauf 2011). Energetic turbulence in the Bornholm basin is confined to the surface and bottom boundary layers, and weak interior mixing has only been observed inside the thermocline and halocline regions where strong nearinertial shear promotes small-scale shear instabilities (Lappe and Umlauf 2016; van der Lee and Umlauf 2011). As shown below, the low turbulence levels in the interior and the intermittent intrusion of waters with a pronounced temperature anomaly provide an ideal environment for the investigation of double-diffusive processes under rapidly varying conditions.

\section{b. Methods}

\section{1) MoOred instrumentation}

The key instrument in our study is an autonomous profiling system (Prien and Schulz-Bull 2016), mounted for a 7-day period from 19 to 26 June 2016 at station $P$ (Fig. 1). The profiler system consists of a buoyant underwater winch, mounted at fixed depth approximately $25 \mathrm{~m}$ above the ground, and a buoyant instrument platform connected to the winch by a Kevlar cable. The instrument platform profiles through the water column above the winch at an average rising speed of approximately $0.3 \mathrm{~m} \mathrm{~s}^{-1}$ with a sampling interval of $30 \mathrm{~min}$.

Stratification parameters were obtained from a multiparameter sonde (CTD 90M from Sea and Sun Technology, Germany), which also includes sensors for conductivity, temperature, and pressure. Vertical molecular heat fluxes through the interfaces of the double-diffusive staircases were computed based on high-resolution temperature data from two FP07 fast thermistors, mounted at the top of the profiling platform, approximately $0.5 \mathrm{~m}$ above any other parts, to avoid contamination by instrumentinduced fluid motions. The FP07 sensors were horizontally separated by a distance of $0.34 \mathrm{~m}$, allowing for a study of the small-scale lateral variability of the diffusive staircases.

The fast thermistors were part of a custom-built turbulence package from Rockland Scientific International Inc. (Canada), which consisted of a logger system and two MicroPod-T sensor units with 2-m flexible leads. The sensors were sampled at a rate of $512 \mathrm{~Hz}$ and are estimated to have a (double pole) response time of approximately $10 \mathrm{~ms}$ (Sommer et al. 2013b), corresponding to an effective vertical resolution of $3 \mathrm{~mm}$ for typical rising speeds. Sommer et al. (2013b) found that this time response of the sensors influences the measurement of interface thicknesses, and hence also the heat fluxes. The correction is largest for the thinnest interfaces, and at our profiling speed of $0.3 \mathrm{~m} \mathrm{~s}^{-1}$ a correction of approximately $15 \%$ must be applied to a $2-\mathrm{cm}$ interface, resulting in a true interface thickness of $1.7 \mathrm{~cm}$. As the thinnest diffusive interfaces found in our study are of the same order of magnitude, this implies a small underestimation of the molecular heat fluxes, which should be kept in mind when interpreting the results discussed in the following.

Velocities were obtained from two acoustic Doppler current profilers (ADCPs) deployed in the vicinity of station $\mathrm{P}$, close to the profiling platform described above. One bottom-mounted 300-kHz ADCP (Workhorse from Teledyne Instruments, United States) sampled nearly the entire water column in 2-m vertical bins at a rate of $1 \mathrm{~Hz}$. High-resolution velocity estimates in the near-surface region were obtained from an upwardlooking $600-\mathrm{kHz}$ Workhorse ADCP, mounted at approximately $30 \mathrm{~m}$ below the surface. This instrument was programmed to sample in $0.5 \mathrm{~m}$ vertical bins at a rate of $1 \mathrm{~Hz}$.

\section{2) SHIP-BASED MEASUREMENTS}

Full-depth high-resolution profiles of stratification parameters were obtained with the help of a MSS90-L microstructure profiler from ISW Wassermesstechnik (Germany), which transmitted data online to the ship while freely falling through the water column at a speed of $0.5-0.7 \mathrm{~m} \mathrm{~s}^{-1}$. This instrument was equipped with precision CTD sensors from Sea and Sun Technology (Germany), two PNS06 shear microstructure sensors from ISW, and one FP07 fast thermistor, all sampled at a rate of $1024 \mathrm{~Hz}$. Here, only data from the CTD sensors will be discussed.

\section{3) OCEAN GLIDER MEASUREMENTS}

A Teledyne Webb Research Slocum Electric shallow ocean glider was deployed on 19 June 2016 and recovered on 26 June 2016. The sensor suite comprised a pumped CTD system (Sea-Bird, Glider Payload CTD), sampling at $1 \mathrm{~Hz}$, and a Rockland Scientific MicroRider-1000 turbulence package to measure temperature microstructure and pressure. The MicroRider-1000 carried two FP07 temperature probes measuring at $512 \mathrm{~Hz}$, whereas the pressure was measured at $64 \mathrm{~Hz}$. Salinity and 
potential density data, used in section 4 , were calculated from the glider CTD data after a two-step correction procedure. First, errors due to a short-time mismatch between temperature and conductivity readings were reduced by lagging the conductivity readings by $0.35 \mathrm{~s}$ using a first-order Butterworth filter. Second, a thermal lag correction procedure was applied, following Garau et al. (2011).

The glider was programmed to survey the upper $40 \mathrm{~m}$ of the water column along an approximately $31-\mathrm{km}$-long east-west transect centered about station P (Fig. 1). On average, the rate of descent (ascent) was $0.17 \mathrm{~m} \mathrm{~s}^{-1}$ $\left(0.12 \mathrm{~m} \mathrm{~s}^{-1}\right)$, yielding down-up profiles at roughly 10 -min intervals. With a typical horizontal speed through water of about $0.25 \mathrm{~m} \mathrm{~s}^{-1}$, two successive downcasts are, on average, separated by approximately $160 \mathrm{~m}$. However, because of current shear the spatial distance between successive downcasts may be depth dependent. To analyze the lateral structure of double-diffusive steps (section 4 ), the spatial distance between the $i$ th profile and the next for a reference depth $z_{\text {ref }}$ is calculated from

$$
S_{i}=\int_{t_{i}}^{t_{i+1}} \mathbf{u}(d(t), t)-\mathbf{u}\left(z_{\text {ref }}, t\right)+\mathbf{u}_{g}(t) d t,
$$

where $t$ is time, $d(t)$ is the depth of the glider as function of time, $\mathbf{u}(z, t)$ is the horizontal current vector as function of depth and time as measured by the moored ADCP (see above), and $\mathbf{u}_{g}(t)$ is the horizontal glider velocity relative to the ambient water, as computed using the flight model of Merckelbach et al. (2010). Here $t_{i}$ represents the time at which the depth of the glider $d\left(t_{i}\right)$ equals $z_{\text {ref }}$ for downcast $i$.

\section{4) COMPUtATION OF DIFFUSIVE HEAT FLUXES}

Different models have been suggested for the computation of the interfacial fluxes in diffusive staircases. Following dimensional arguments, these usually relate the heat flux to the $4 / 3$ power of the temperature difference across the interface. Here, we compute both the density ratio $R_{\rho}$, defined in (1), and the heat flux based on the differences of Conservative Temperature $\Delta \Theta$ and Absolute Salinity $\Delta S_{\mathrm{A}}$ across the interface, following the international Thermodynamic Equation of Seawater 2010 (TEOS-10) standard (IOC et al. 2010). The most popular model of this type has been described by Kelley (1990):

$$
F=\Phi\left(R_{\rho}\right) \rho c_{p}^{0}\left(\alpha g \kappa^{2} \nu^{-1}\right)^{1 / 3} \Delta \Theta^{4 / 3},
$$

where $\rho$ is the in situ density, $g$ is the acceleration of gravity, and $c_{p}^{0}$ is a constant reference heat capacity that is part of the TEOS-10 standard. The molecular diffusivities of heat and momentum, $\kappa$ and $\nu$, were computed according to Sharqawy et al. (2010) as functions of temperature and salinity. The function $\Phi$ depends on the density ratio defined in (1):

$$
\Phi_{\mathrm{K} 90}=0.0032 \exp \left(4.8 R_{\rho}^{-0.72}\right) .
$$

A modified version,

$$
\Phi_{\mathrm{FLR} 13}=0.0157+0.0505\left(R_{\rho}-1\right)^{-1.24}
$$

was recently suggested by Flanagan et al. (2013).

Using the high-resolution temperature data from the FP07 fast thermistors (see above), we computed molecular fluxes across the diffusive interfaces from the vertical gradient of Conservative Temperature:

$$
F_{m}=-\rho c_{p}^{0} \kappa \frac{\partial \Theta}{\partial z}
$$

Lacking high-resolution conductivity data, we estimated the Conservative Temperature $\Theta$ in the interface region based on the average of the conductivities in the layers above and below the interface, respectively. The associated uncertainties turned out to be negligible.

Further details about the selection of diffusive staircase regions, the computation of layer-averaged quantities, and the estimation of representative heat fluxes are summarized in the appendix.

\section{Vertical structure}

\section{a. Background conditions}

The vertical structure of the water column at position $\mathrm{P}$ is summarized in Fig. 2, showing full-depth profiles of the most important stratification parameters obtained from the MSS90 microstructure profiler at the beginning and end of the observation period, respectively. The most prominent features are a seasonal thermocline around $20-30 \mathrm{~m}$ depth, and a permanent halocline below approximately $50 \mathrm{~m}$ depth that intersects with the sloping bottom. The observation period was characterized by weak winds and strong solar insolation, which is reflected in a rapid warming of the surface waters. As evident from Fig. 2a, this resulted in the evolution of a secondary shallow thermocline associated with strong near-surface stratification above approximately $10 \mathrm{~m}$ depth. The region below $10 \mathrm{~m}$ depth, to which most of the following observations will be confined, was thus isolated from surface-layer turbulence. Note that the average temperature in the uppermost $40 \mathrm{~m}$ decreases with depth, indicating that the largescale vertical stratification is stable with respect to 


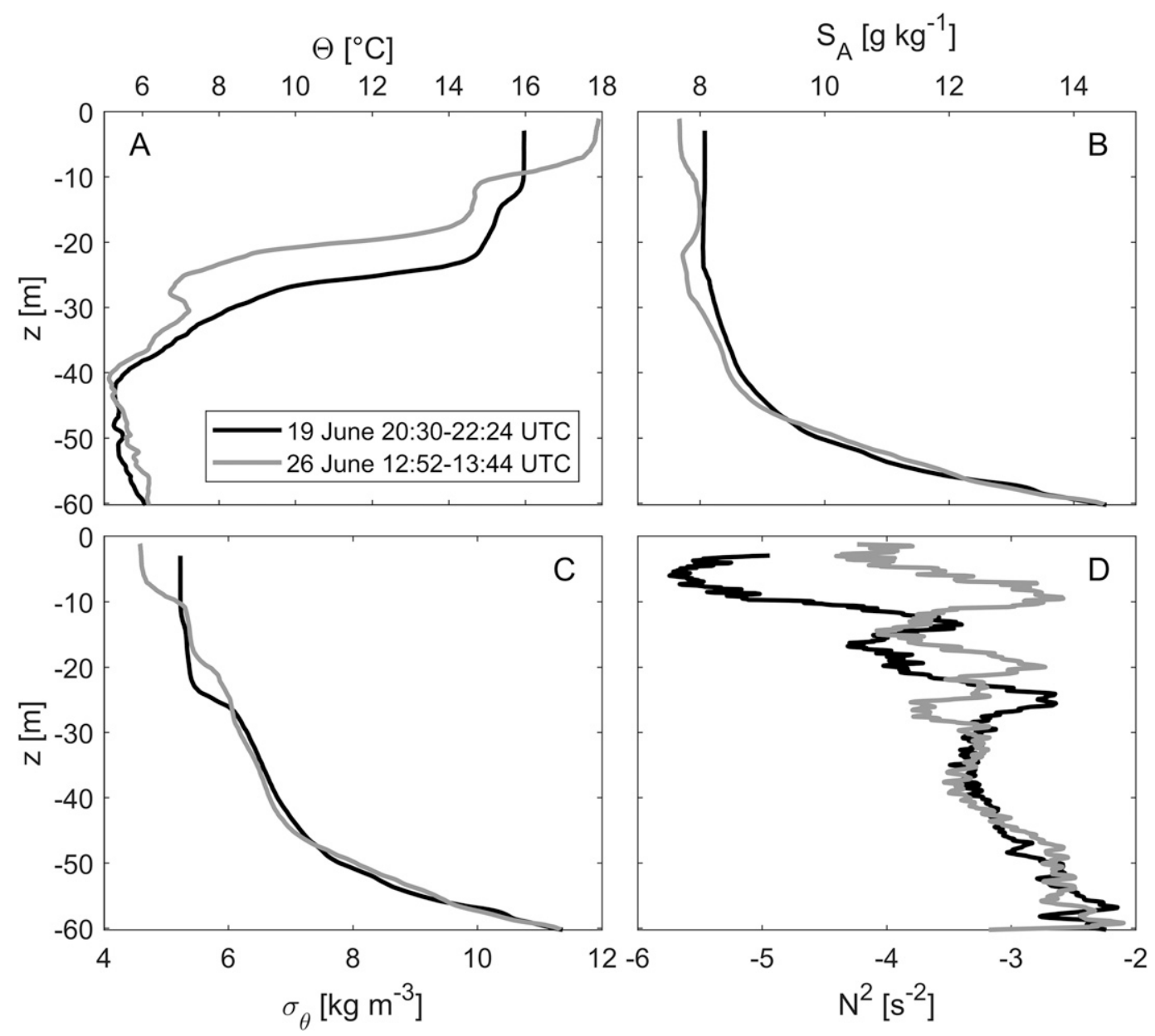

FIG. 2. Vertical structure of (a) Conservative Temperature, (b) Absolute Salinity, (c) potential density, and (d) buoyancy frequency squared at the beginning (black) and end (gray) of the deployment period of the autonomous profiling platform. Profiles are based on the averages of 33 and 17, respectively, full-depth casts with the MSS90 microstructure profiler.

double-diffusive instabilities. As shown below, however, diffusive staircases may still develop on the small-scale temperature anomalies associated with intrusions.

The pycnoclines formed by the thermocline and halocline are characteristic for summer conditions in the Baltic Sea. They determine the motions in the internal wave band, which are dominated by low-mode nearinertial waves with inflection points inside these interfaces (van der Lee and Umlauf 2011). The signature of near-inertial waves can also be clearly identified, especially in the halocline region, in the velocity records shown in Fig. 3. Note the near-surface inflection point in the vicinity of the developing secondary thermocline that slowly rises from approximately $10 \mathrm{~m}$ at the beginning of the record to 6-7 $\mathrm{m}$ at the end. Assuming that this inflection marks the lower limit of the surface mixed layer (across which the atmospheric momentum input takes place), we find additional support for the above conclusion that surface turbulence is confined to a region shallower than $10 \mathrm{~m}$.

Previous studies have shown that mixing due to smallscale shear instabilities below the surface layer is largely confined to the halocline region (van der Lee and Umlauf 2011) and to an energetic bottom boundary layer of a few meters thickness (Lappe and Umlauf 2016). As pointed out by van der Lee and Umlauf (2011), shear-induced mixing is virtually lacking in the region between the thermocline and the halocline, which is important for the following discussion of double-diffusive mixing in the same depth range. Figure 3 shows that on 23-24 June 2016, when the double-diffusive staircases discussed in the following were detected, the region above $30 \mathrm{~m}$ depth was determined by a weakly sheared northwesterly mean current with speeds in the range $0.1-0.2 \mathrm{~m} \mathrm{~s}^{-1}$, and only 


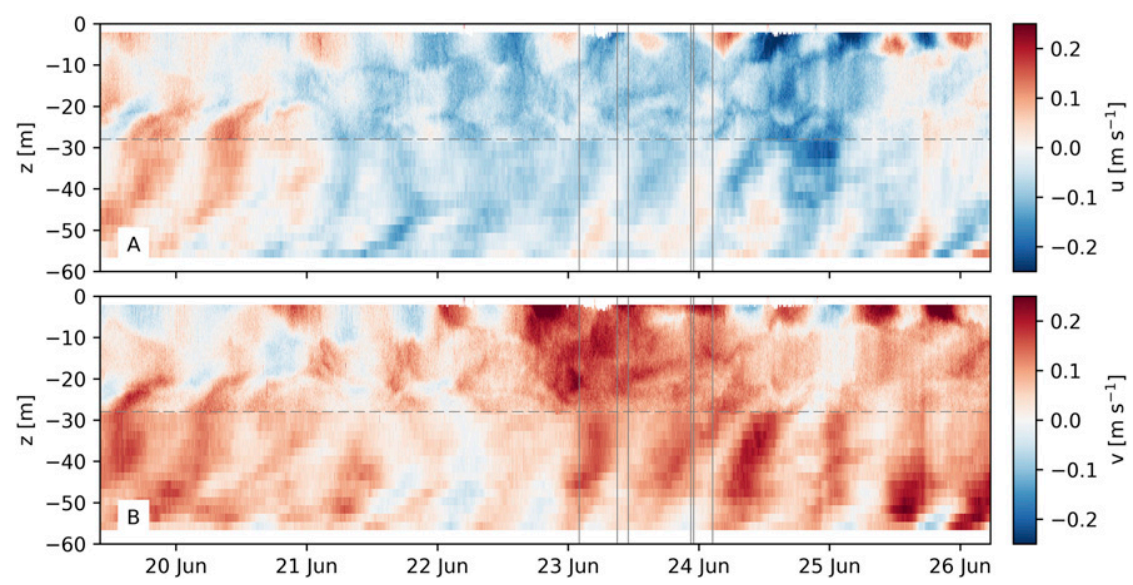

FIG. 3. Time series of the (a) east and (b) north components of the velocity at position P (see Fig. 1) for a period of approximately one week in June 2016. Velocities are based on data from a bottom-mounted $300-\mathrm{kHz}$ ADCP (below dashed line), and an upward-looking $600-\mathrm{kHz}$ ADCP mounted at approximately $30 \mathrm{~m}$ depth. Vertical gray lines indicate the positions of vertical profiles shown in Figs. 5 and 6.

weak near-inertial wave activity. Except for the uppermost meters, the overall vertical shear in this region was thus small.

\section{b. Intrusions and diffusive staircases}

Data from the autonomous profiling station at station $\mathrm{P}$ are shown in Fig. 4. The nominal sampling range of the station is approximately $12-32 \mathrm{~m}$ depth; however, because of winch problems, the upper edge of the sampling range gradually descended during the deployment. Figures $4 \mathrm{a}$ and $4 \mathrm{~b}$ show that the stable salinity and temperature gradients that generally characterized the water column were intermittently disturbed by cold and fresh intrusions with a vertical scale of a few meters. While these intrusions are readily identified in the salinity records (Fig. 4a), their effect on temperature becomes clearly visible only after subtracting the isopycnally averaged temperatures for the entire deployment period (Fig. 4c). The strongest intrusions were observed on 23-24 June, and in the early morning of 26 June at the end of the deployment period. Intrusive temperature anomalies during these periods were of the order of $1 \mathrm{~K}$, which also sets the temperature range of the double-diffusive step structures discussed in the following. The origin of these cold and fresh intrusions cannot be determined from our single-point measurements, but it is likely that they represent water masses intruding via the Stolpe Channel from the colder and less salty basins in the eastern part of the Baltic Sea (Fig. 1). This is also consistent with the westerly velocities during and before the arrival of the intrusions (Fig. 3a).

Despite the overall stable vertical temperature gradient at station $\mathrm{P}$, regions with local temperature inversions in the vicinity of the intrusions are ubiquitous features in our high-resolution data. The examples in Fig. 5 show that these intrusions are characterized by vertical scales and temperature anomalies of the order of $1 \mathrm{~m}$ and $0.1-1 \mathrm{~K}$, respectively. They evolve quickly on time scales of hours, and the same intrusions were typically sampled only in a single or a few casts of the autonomous profiling platform. It is likely that the observed rapid variability mirrors the lateral advection of temperature anomalies past our measurement site rather than the effect of local processes (e.g., mixing). As indicated by the red and blue shaded areas in Fig. 5, these temperature anomalies may be interpreted either as warm intrusions into a cold environment or, vice versa, as intrusions of cold water into warmer ambient fluid. While Fig. 4c suggests that the latter interpretation is more likely, a clear distinction between these two types of intrusions cannot always be made in view of the variable background conditions. This is, however, of little consequence for the following conclusions as warm and cold intrusions are characterized by similar vertical scales and temperature anomalies.

A closer inspection of Fig. 5 shows a striking asymmetry between the upper and lower edges of the temperature anomalies discussed above. Whereas the lower edges of warm anomalies (and, vice versa, the upper edges of cold anomalies) exhibit smooth temperature gradients, the upper edges of warm (and lower edges of cold) anomalies are characterized by sharp temperature steps alternating with nearly perfectly mixed layers, thus providing direct evidence for the development of double-diffusive staircases. As exemplified in Fig. 5, and discussed in more detail below, these staircase regions generally consist of only a few well-defined steps (typically $1-4$ in our dataset, and rarely more than 5). 


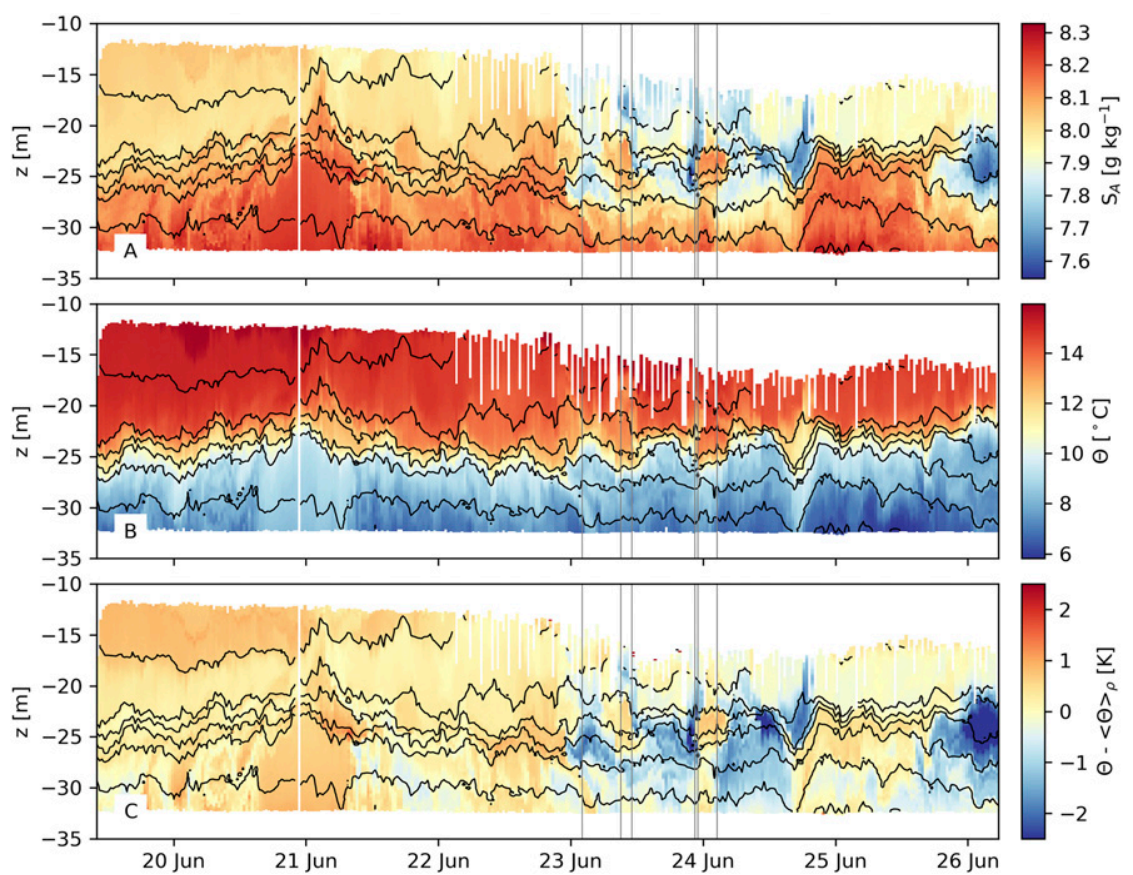

FIG. 4. Temporal evolution of (a) Absolute Salinity, (b) Conservative Temperature, and (c) temperature anomaly with respect to the isopycnal time average, all based on data from the profiling platform moored at position $\mathrm{P}$ (see Fig. 1). Isopycnals (black lines) are shown at $0.2 \mathrm{~kg} \mathrm{~m}^{-3}$ intervals. Vertical gray lines indicate the positions of vertical profiles shown in Figs. 5 and 6. The time period is identical to that shown in Fig. 3.

\section{c. Staircase structure and diffusive fluxes}

Figure 6 shows a high-resolution view of the temperature structure inside the staircase regions identified in Fig. 5 (the panel numbering is identical). Note that Figs. 5 and 6 show in situ rather than Conservative Temperatures as microconductivity data at comparable resolution, required for the precise computation of the latter (IOC et al. 2010), were not available. Figure 6 reveals that the interfaces inside the staircase regions at the upper edge of the warm temperature anomalies (or, vice versa, at the lower edge of the cold anomalies) have a thickness of only a few centimeters, and separate well-mixed layers with a thickness of the order of $0.1-1 \mathrm{~m}$. Remarkable are the extreme temperature differences of up to $1.5 \mathrm{~K}$ across single interfaces (Figs. $6 \mathrm{~d}, \mathrm{e})$. A careful calculation of temperature and salinity steps across individual interfaces, described in detail in the appendix, shows that density ratios as small as $R_{\rho}=1.3-1.5$ may be reached in these cases (Figs. 6c-e).

In diffusive convection, the molecular heat flux $F_{m}$ through the diffusive interfaces is believed to represent the heat flux through the staircase region. If temperature microstructure data are available, the temperature gradient required for the computation of the molecular flux is often obtained from fitting a linear temperature profile over a subregion of the interface (Sommer et al. 2013b, 2014; Guthrie et al. 2015). In our low- $R_{\rho}$ data, however, the application of this method is complicated by small-scale irregularities inside the interfaces and surprisingly large differences in the interface structure and thickness between the two available FP07 thermistors, separated by a horizontal distance of only $0.34 \mathrm{~m}$ (see, e.g., Figs. 6d-f). It is worth noting that the striking differences in the interface structure over distances of only a few decimeters are consistent with the direct numerical simulations of Sommer et al. (2014) at low $R_{\rho}$ (see their Fig. 2). As a consequence, rather arbitrary assumptions turned out to be required to define the interface region used for the fitting procedure, and the resulting heat fluxes often differed by more than an order of magnitude between the two sensors.

A more robust representation of the interfacial flux is the molecular flux found at the location with the maximum temperature gradient inside the interface, that is, with the maximum diffusive flux, as originally suggested by Sirevaag and Fer (2012) and discussed in more detail in the appendix. Support for this definition comes from the following arguments:

1) As shown in Fig. 6, the molecular fluxes computed this way show only a small variability (typically 

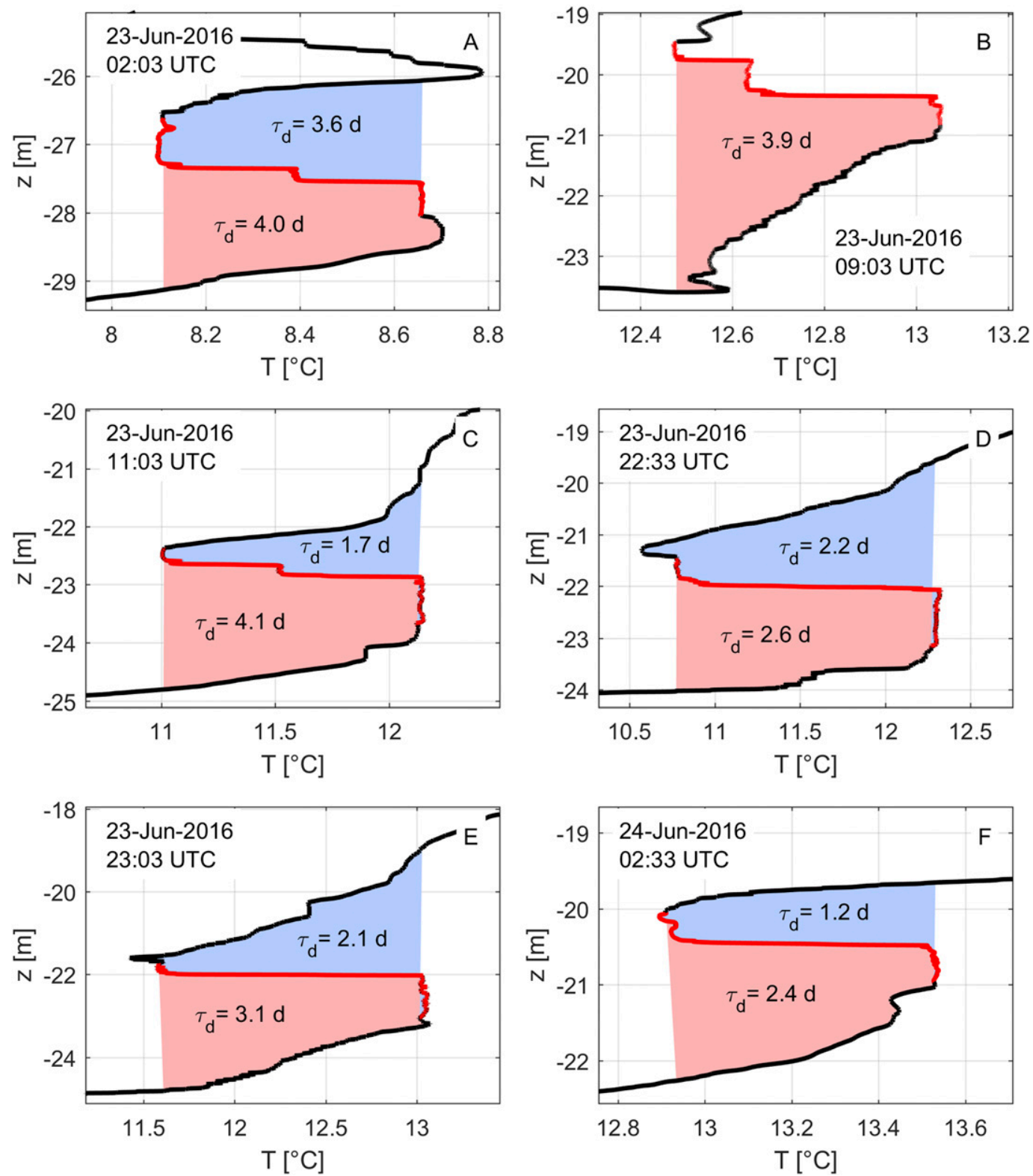

FIG. 5. In situ temperature profiles in the vicinity of warm (red shaded) and cold (blue shaded) temperature anomalies induced by intrusions (profile positions are indicated in Fig. 4). Data are based on the FP07 microstructure sensors mounted on the profiling platform. Diffusive staircase regions evolving on the upper edge of the warm temperature anomalies are marked in red (a detailed view is shown in Fig. 6). The decay time scale $\tau_{d}$ of intrusions due to double-diffusive mixing is indicated for each example.

$10 \%-20 \%$ ) between the two sensors, despite the obviously large differences in interface structure and location of maximum gradients (black dots).

2) A reanalysis of the direct numerical simulations of diffusive convection at low $R_{\rho}$ by Sommer et al. (2014) shows that the maximum diffusive fluxes approximate the total interfacial fluxes within approximately $10 \%$ (details are discussed in the appendix).
3) No arbitrary assumptions, for example, about the interface structure or thickness, are required for the application of the method.

Figure 6 shows that the large temperature differences across interfaces are mirrored in exceptionally large diffusive heat fluxes. The largest fluxes in our dataset $\left(\approx 50 \mathrm{~W} \mathrm{~m}^{-2}\right)$ are observed in staircases with a 

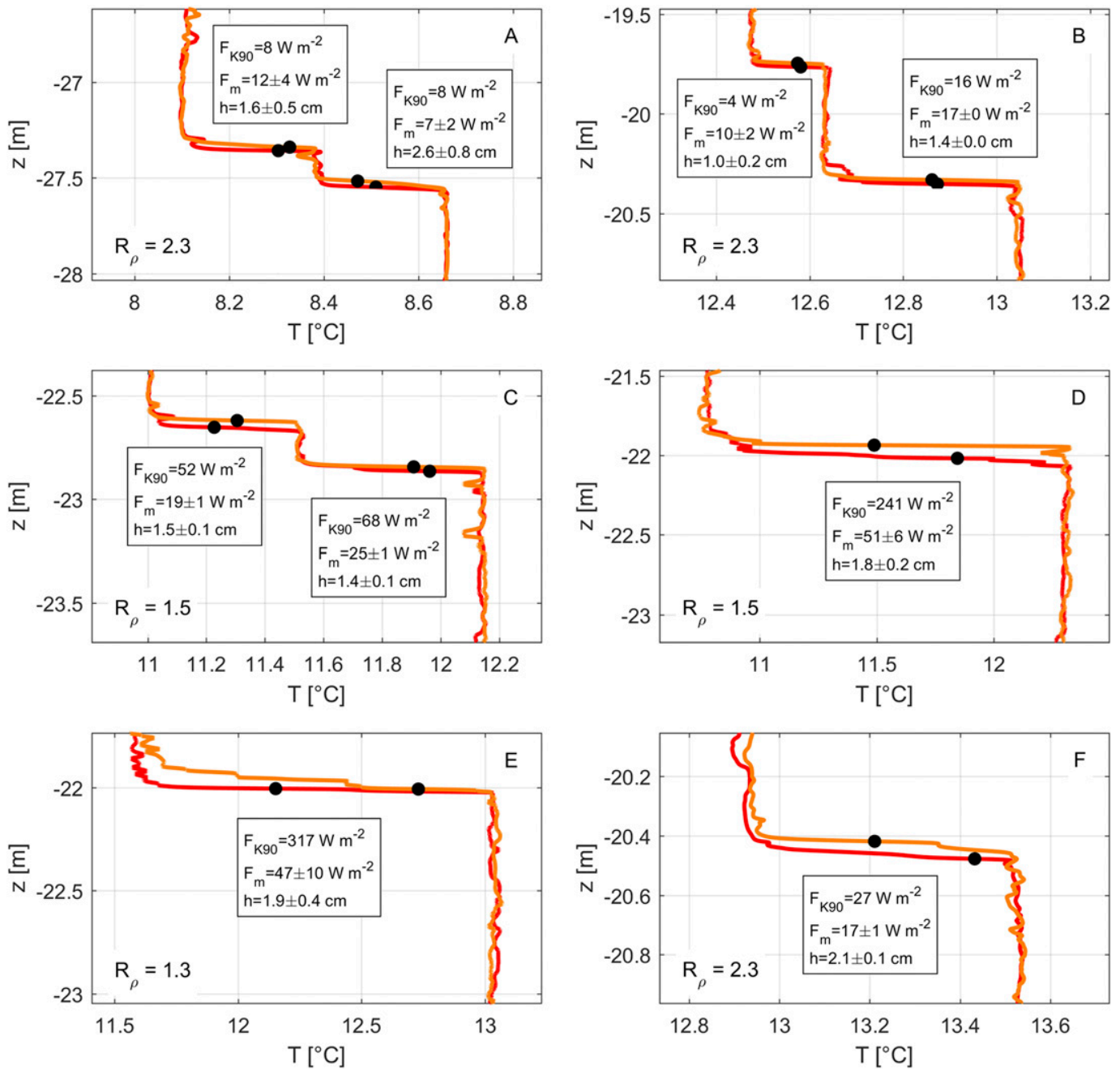

FIG. 6. In situ temperature structure inside the staircase regions shown in Fig. 5 based on data from the two FP07 fast thermistors (red/orange colors) mounted on the autonomous profiling platform. For each diffusive interface, text boxes indicate modeled and observed molecular heat fluxes defined in (3) and (6), respectively, and the diffusive interface thicknesses $h$ computed from (7). Parameters $F_{m}$ and $h$ are based on the averages of the two thermistors with the standard deviations as indicated. Black markers show the locations of maximum molecular fluxes. Note that the panel numbering corresponds exactly to that used in Fig. 5.

single interface, small $R_{\rho}$, and temperature jumps of more than $1 \mathrm{~K}$ (Figs. $6 \mathrm{~d}, \mathrm{e}$ ). However, fluxes of $O(10) \mathrm{W} \mathrm{m}^{-2}$ can also be found in staircases with $R_{\rho}>2$ (Figs. 6a,b,f) and more than one interface (Figs. 6a-c). Interfacial fluxes computed from the frequently used model of Kelley (1990), described in more detail in the context of (3) above, provide a good order-of-magnitude estimate for these fluxes but tend to overestimate the measured molecular fluxes at low $R_{\rho}$ by a factor of 2-6 (Figs. 6c-e). This is discussed in more detail below.

The large heat fluxes imply short decay time scales for the temperature anomalies (intrusions) that delineate the staircase regions in our data. A simple estimate for the decay time scale due to mixing is $\tau_{d}=Q / F_{m}$, where $F_{m}$ is the interfacial heat flux in the staircase region adjacent to the intrusion, and $Q=\int \rho c_{p}^{0}|\tilde{\Theta}| d z$ is its (relative) heat content. Here, $\tilde{\Theta}$ denotes the temperature anomaly associated with the intrusion, and the integral is computed across its vertical extent. Figure 5 shows a few examples, where the blue- and red-shaded areas indicate the relative heat content inside intrusions with positive and negative temperature anomalies, respectively. The values of $\tau_{d}$ shown in Fig. 5 suggest that these structures decay on a time scale of only a few days as a result of doublediffusive mixing. It is interesting to note that intrusions with stronger interfacial heat fluxes (see Fig. 6) do not decay more quickly because both the heat content $Q$ of an intrusion and the interfacial heat flux $F_{m}$ in the 
staircase region adjacent to it are approximately proportional to the temperature anomaly associated with it (assuming that the number of stairs is identical).

Based on the definition of the molecular heat flux $F_{m}$ in (6), the thickness of the diffusive "core" of the interface can be determined (Carpenter et al. 2012):

$$
h=\frac{\rho c_{p}^{0} \kappa \Delta \Theta}{\max \left|F_{m}\right|},
$$

where $\Delta \Theta$ is the (conservative) temperature difference between the layers above and below the interface. The resulting values of $h$ (see Fig. 6) are typically in the range $1-2 \mathrm{~cm}$ with only a small variation between the two sensors that reflects the differences in the computed heat fluxes. Because of the generally asymmetric structure of the interfaces, the location of the core of the interface, according to (7) collocated with the maximum of $F_{m}$, does generally not coincide with the (visually defined) center of the total interface region (see black dots in Fig. 6).

\section{d. Evaluation of heat flux models}

The availability of temperature microstructure data inside staircase regions with low $R_{\rho}$ and exceptionally large $\Delta \Theta$ allowed us to investigate the performance of some frequently used heat flux models in a parameter range that has been rarely studied in the ocean. Our analysis will be exclusively based on data from the profiling system at position $\mathrm{P}$ (see Fig. 1) as uncertainties with the conductivity sensor response and time delay limit the precise computation of $R_{\rho}$ from the glider data. Staircase regions were visually detected (see appendix for details), and molecular and modeled interfacial heat fluxes were computed as described above. This resulted in the identification of 52 well-defined interfaces, spanning approximately two orders of magnitude in heat fluxes, and density ratios in the range $1.3<R_{\rho}<5.6$.

In Fig. 7, the measured interfacial fluxes, identified with the maximum molecular flux inside the interface as described above, are compared to the models by Kelley (1990) and Flanagan et al. (2013), respectively. Both models assume that the heat flux is proportional to the $4 / 3$ power of the interfacial temperature jump $\Delta \Theta$ [see (3) above] but differ slightly in the nondimensional function $\Phi$ that, according to (4) and (5), reflects the dependency of the models on $R_{\rho}$.

Figure 7 shows that both models provide a good representation of the general trend in the data. This is quantified by the relative difference between the modeled and observed molecular fluxes across an interface, $r_{i}=\left|F-F_{m}\right| / F_{m}$, where $F$ and $F_{m}$ are the modeled and measured interfacial fluxes, respectively. Computing the average $\left\langle r_{i}\right\rangle$ over all interfaces results in

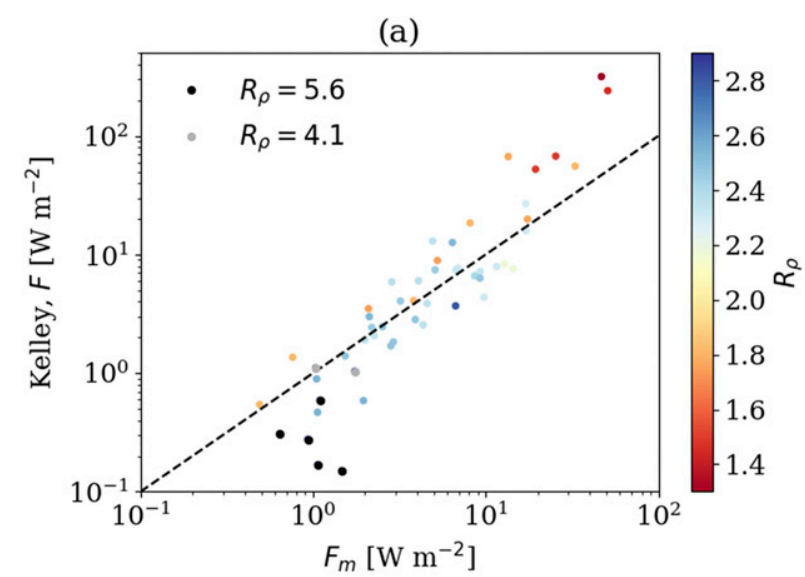

(b)

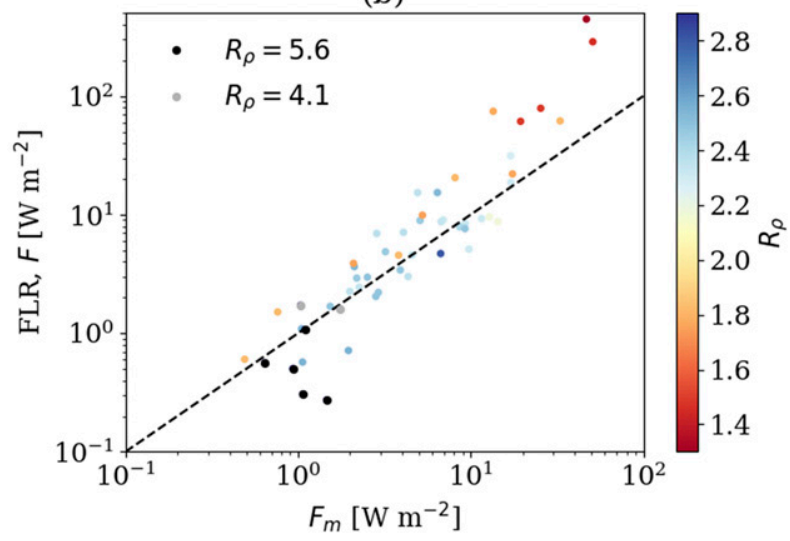

FIG. 7. Comparison of molecular interfacial fluxes with (a) the model of Kelley (1990) and (b) the model of Flanagan et al. (2013), based on data from the autonomous profiling system at position $\mathrm{P}$ (see Fig. 1). Values of $R_{\rho}$ are color coded with out-of-range values specified in the figure legend. The dashed line indicates perfect agreement between modeled and observed molecular fluxes.

$\left\langle r_{i}\right\rangle=0.72$ for the model of Kelley (1990), and a slightly higher value of $\left\langle r_{i}\right\rangle=0.85$ for the model of Flanagan et al. (2013). Both values are of order one, suggesting that, on the average, the models predict the observed interfacial fluxes within a factor of 2, approximately. The largest differences are observed for the largest ( $R_{\rho}=5.6$, black dots) and smallest $\left(1.3<R_{\rho}<1.8\right.$, red to orange dots) density ratios in our dataset. The data points for $R_{\rho}=5.6$ were all taken from a single staircase region with steps that did not always exhibit clear indications for convecting (i.e., well mixed) layers, which might explain the deviations.

A greater disagreement between modeled and measured heat fluxes at $1.3<R_{\rho}<1.8$ is not particularly surprising. The Kelley (1990) parameterization is based on laboratory data that exhibits significant scatter for low $R_{\rho}$, and the modification by Flanagan et al. (2013) used numerical simulations for $R_{\rho} \geq 2$ to propose a correction 

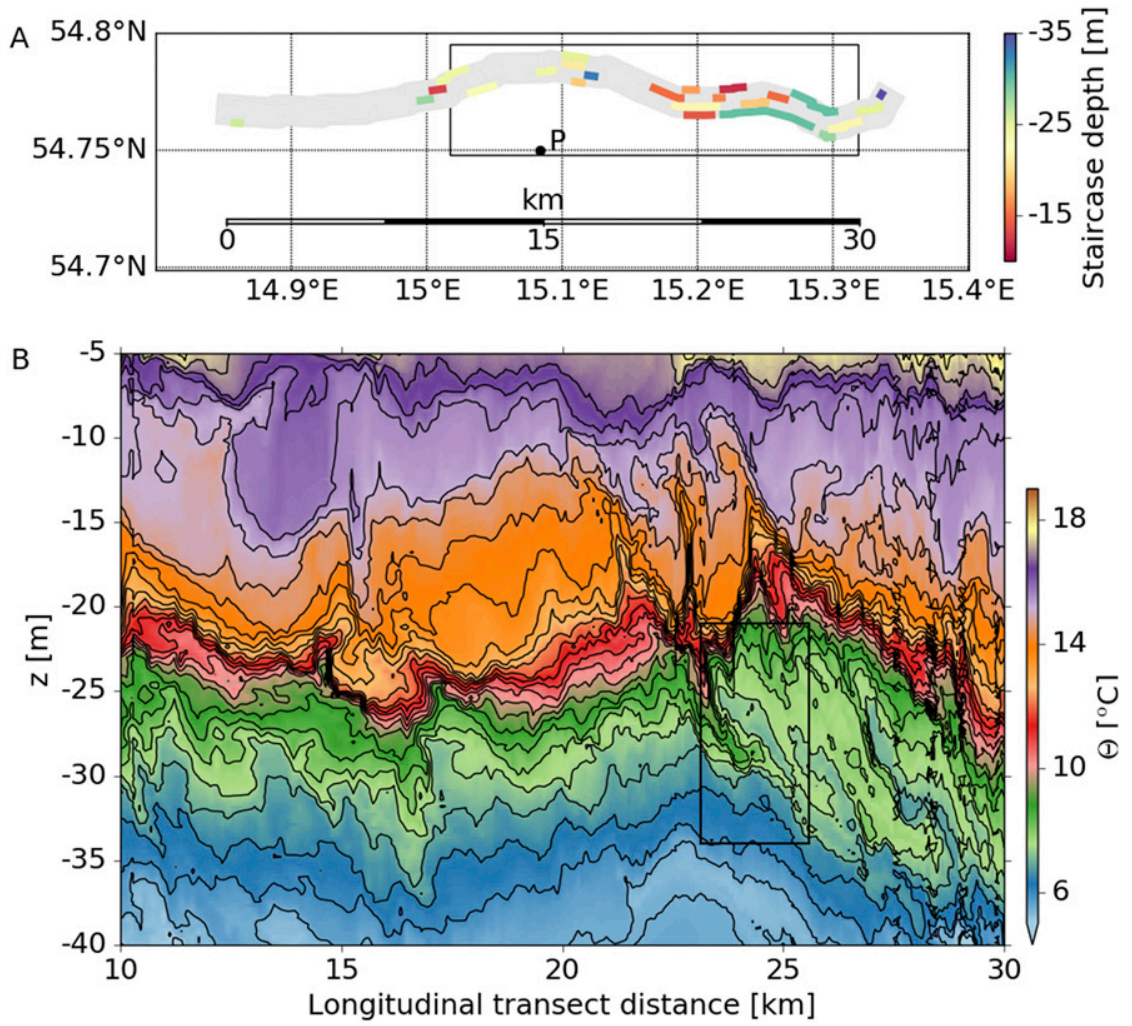

FIG. 8. Coverage and lateral structure of Baltic Sea double-diffusive intrusions from the glider transect shown in Fig. 1. (a) Map of the glider transect (gray) performed during a 60-h period starting at 0530 UTC 23 Jun 2016. Thinner colored lines overlaid on the transect denote the location of double-diffusive staircase regions, with the colors indicating the representative depth of the staircases. (b) Conservative Temperature field measured by the glider along the section of the transect denoted by the box in (a). The horizontal axis represents the distance traveled by the glider in the longitudinal direction. The box in (b) denotes the location of the profiles shown in Fig. 9.

for larger $R_{\rho}$ regimes. However, the large increases in the heat flux at these very low $R_{\rho}$ interfaces are primarily a result of the exceptionally large $\Delta \Theta$ values associated with them, with $0.5^{\circ} \mathrm{C}<\Delta \Theta<1.6^{\circ} \mathrm{C}$. Discrepancies with the modeled fluxes could then be contributed by uncertainties in the scaling exponent for the Rayleigh number Ra, which also determines the exponent for $\Delta \Theta$. This is reflected in the differences between modeled and measured heat fluxes at the largest fluxes in Fig. 7. Numerous studies have suggested a lowering of the scaling exponent based on numerical, observational, theoretical, and laboratory results (e.g., Kelley et al. 2003; Sommer et al. 2013a; Hieronymus and Carpenter 2016), but there is no generally agreed-on exponent.

\section{Lateral structure}

Using the glider survey, it is possible to characterize the lateral structure of the intrusions and the diffusive convection that they form. Figure 8 a shows a single east-west glider transect performed over a 60 -h period, and covering a longitudinal distance of $31 \mathrm{~km}$ (location shown in Fig. 1). It was found to exhibit a multitude of different intrusions with evidence of double-diffusive steps. The double diffusion occurs at different depths in the water column, sometimes with multiple vertically staggered intrusions at the same position. The spatial coverage and representative depths of the double-diffusive structures along the transect are shown in Fig. 8a. We interpret the structures observed in this transect as spatial variability, since they have estimated time scales of days, but have been transected over a duration of hours (i.e., the glider moves roughly $2.5 \mathrm{~km}$ through water every $3 \mathrm{~h}$ ).

A longitudinal slice of $20 \mathrm{~km}$ in length of the temperature field that is particularly rich with intrusions and double-diffusive step structures is shown in Fig. 8b. It reveals the geometry of the intrusive structures, which extend as a series of "tails" both laterally and vertically through the water column at $10-35 \mathrm{~m}$ depth. The lateral scales of the double-diffusive intrusion structures range 

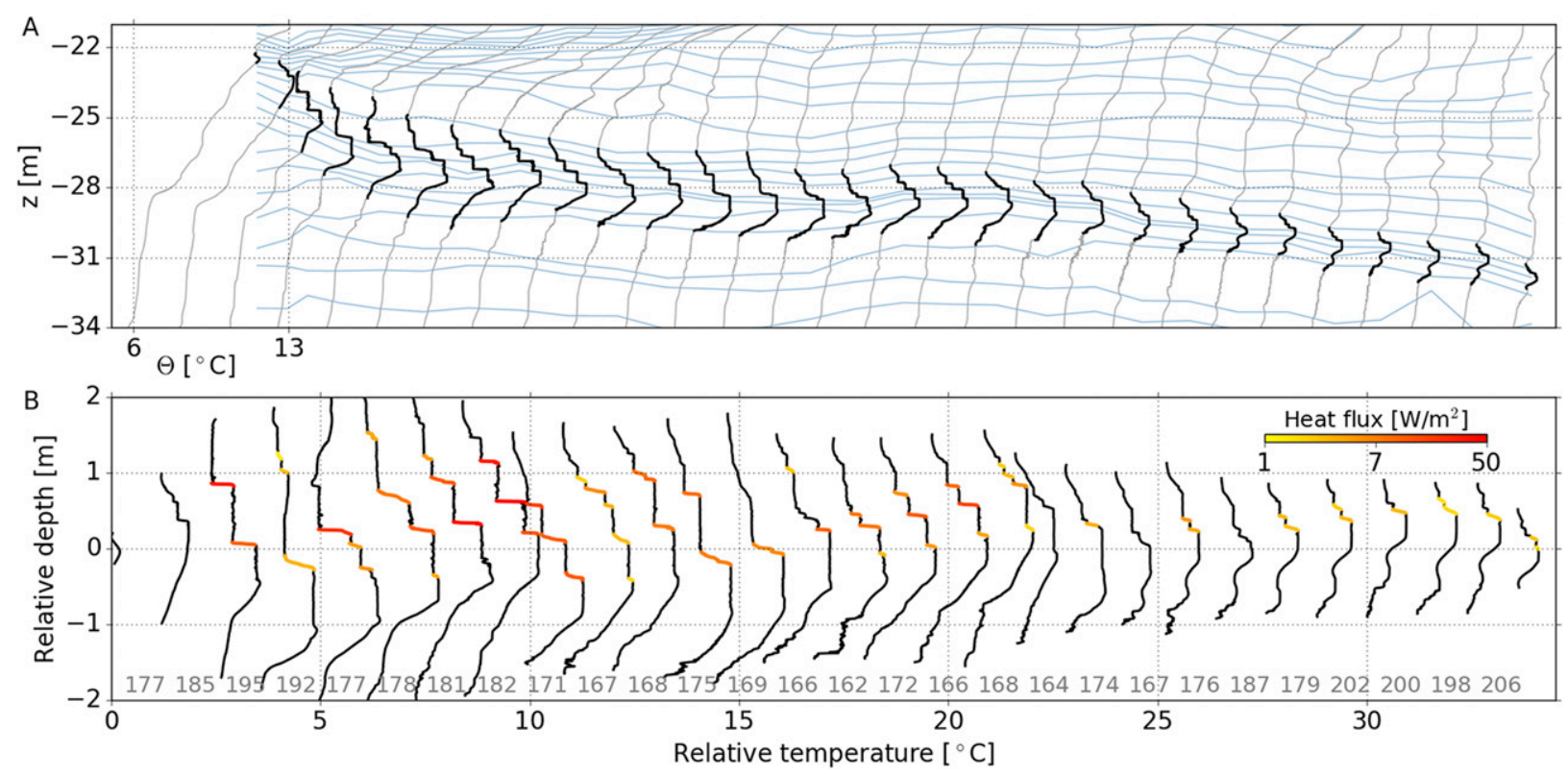

FIG. 9. Glider-based profiles of double-diffusive staircases in a single intrusion, measured by the temperature microstructure sensor. Each plotted profile represents a successive downcast of the glider measured over a 5.25-h period beginning at 1544 UTC 24 Jun 2016. (a) Conservative Temperature profiles (gray) successively offset by $2.2^{\circ} \mathrm{C}$, with the intrusion highlighted with thick dark lines (and assumed warm). The blue lines indicate the depth of isopycnals plotted in intervals of $0.05 \mathrm{~kg} \mathrm{~m}^{-3}$. (b) Centered plots of the intrusion identified in (a) to show the double-diffusive staircase structures. The estimated distance $(\mathrm{m})$ between profiles is shown at the bottom of the plot. Each profile in (b) is offset by $1.2^{\circ} \mathrm{C}$. Measured heat fluxes for selected double-diffusive interfaces are shown using the logarithmic color scale in (b).

between kilometers to hundreds of meters. However, there is considerable variability in the individual layers over lateral scales that are much smaller than the intrusive structures. This can be seen in Fig. 9, where successive individual downcast temperature profiles from a $4.8-\mathrm{km}$ $(5.25 \mathrm{~h})$ section of the glider transect are plotted. This shows that there is significant vertical migration of the double-diffusive staircase, which follows the top flank of the intrusion (assuming it is a warm anomaly). The changing depth of the intrusion is also accompanied by a crossing of isopycnals as seen in Fig. 9a.

Another striking feature is the variability in the double-diffusive staircase structure between casts, with successive casts often showing little resemblance of the layers. This demonstrates a horizontal coherency of the double-diffusive layers that is less than the mean distance between downcasts of approximately $180 \mathrm{~m}$, with individual distances between staircase measurements indicated in Fig. 9b. When comparing the staircase layering with consecutive upcasts and downcasts of the glider, with a mean distance of $40 \mathrm{~m}$ between staircase measurements, coherency was found in the majority of profiles (not shown). This indicates an approximate horizontal range over which the double-diffusive staircase layers lose coherency of between 40 and $180 \mathrm{~m}$-an estimate that is considerably smaller than the smallest reported value of several hundreds of meters from Lake
Kivu (Schmid et al. 2010), and dramatically different than the hundreds of kilometers found in the Canada basin, Arctic Ocean (Timmermans et al. 2008).

Also apparent from Fig. 9b is the large range and spatial variability that are present in the individual layer heat fluxes. Within this intrusion, differences in the measured molecular heat flux between adjacent interfaces within the same profile are as high as $26 \mathrm{~W} \mathrm{~m}^{-2}$, with a mean value of $7.0 \mathrm{~W} \mathrm{~m}^{-2}$. We also observe a strong lateral variability of the vertical heat fluxes between adjacent profiles with maximum differences as high as $38 \mathrm{~W} \mathrm{~m}^{-2}$, and a mean difference of $12 \mathrm{~W} \mathrm{~m}^{-2}$.

These large heat flux divergences suggest a rapid, laterally variable evolution of the staircase regions. A time scale can be constructed for individual layers with heat content $Q=\rho c_{p}^{0} \Delta \Theta H$, and a heat flux divergence given by the difference between adjacent interfaces in the same vertical profile. From the glider transect shown in Fig. 9, which exhibits an average flux difference between interfaces of $\Delta F_{m}=7.0 \mathrm{~W} \mathrm{~m}^{-2}$, and using the mean values shown for the glider staircases in Fig. 10, we arrive at a representative layer time scale of approximately 0.5 days. This may be compared to estimates in the Arctic staircases of layer merging time scales of the order of several days (Radko et al. 2014); however, it is not clear whether the onedimensional analysis presented in Radko et al. (2014) is applicable to such laterally variable staircases as we observe. 

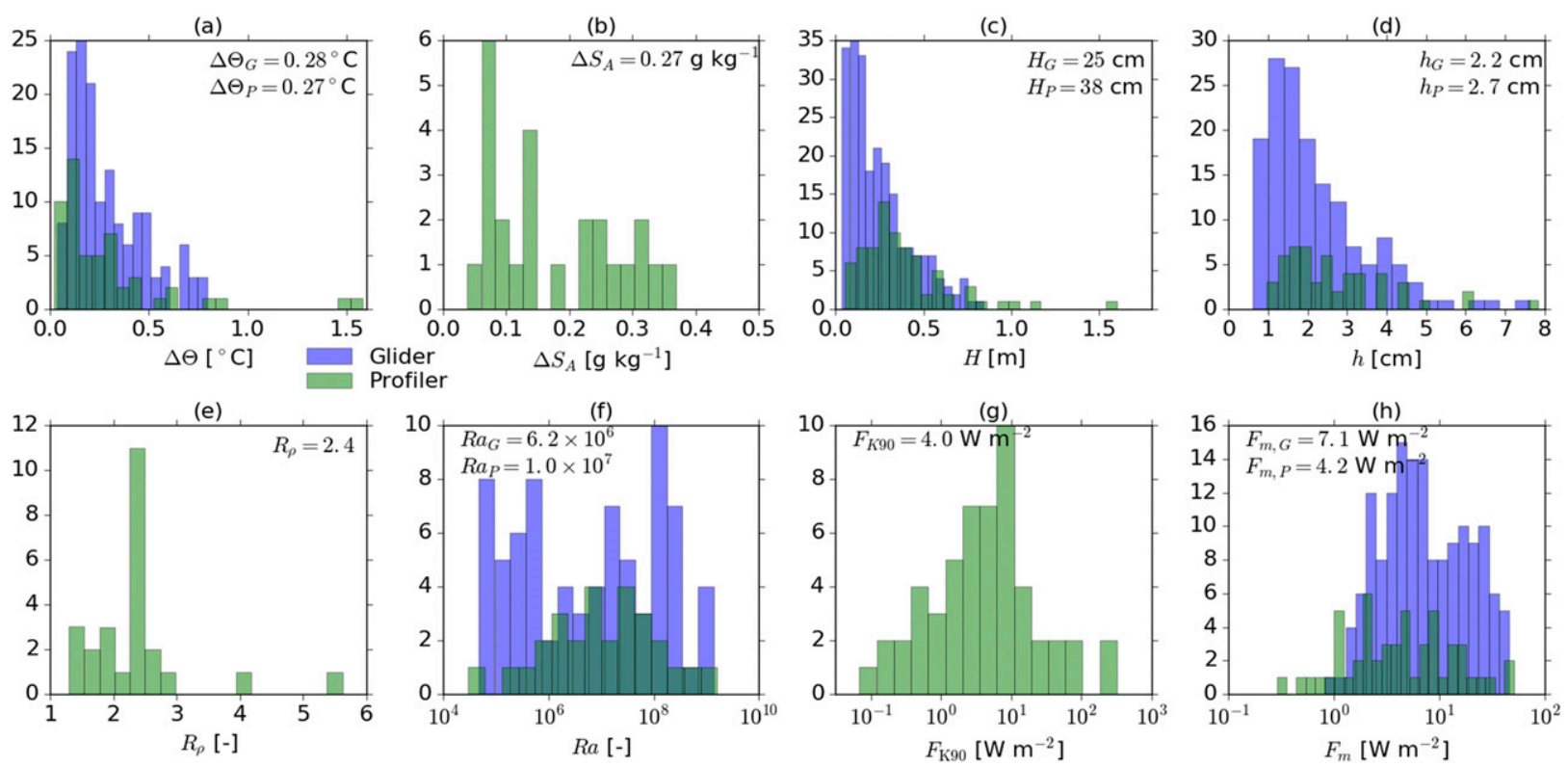

FIG. 10. Summary of the distributions of relevant double-diffusive staircase parameters: (a) temperature steps, (b) salinity steps (only available accurately for profiler data), (c) mixed layer thicknesses, (d) interface thicknesses calculated from (7), (e) density ratios, (f) Rayleigh numbers, (g) heat fluxes from the Kelley (1990) parameterization, and (h) measured heat fluxes. Colors indicate data collected by either the profiler or the glider. Arithmetic averages are shown in each panel, with geometric means used in (f)-(h) due to the logarithmic axis and skewed distributions.

\section{Discussion and conclusions}

A particularity of our observations is the exceptionally large double-diffusive heat fluxes of $O(10) \mathrm{W} \mathrm{m}^{-2}$ that exceed typical values in the Arctic Ocean by approximately two orders of magnitude (Timmermans et al. 2008; Guthrie et al. 2015; Shibley et al. 2017). This can be traced back to both a factor of 10-100 larger temperature steps across individual interfaces, as well as the comparatively small values of $R_{\rho}$. Whereas the Arctic staircases vary between $R_{\rho}=3$ and $R_{\rho}=7$ depending on geographic location (Shibley et al. 2017), our observations are clustered around $R_{\rho}=2$ (see Fig. 10 for a summary of the frequency distributions of staircase parameters). For the same reasons, our diffusive heat fluxes are also a factor 100-1000 larger than those found in some lakes with well-developed diffusive staircases (Sommer et al. 2013b; Scheifele et al. 2014). A notable exception is the observations of Sánchez and Roget (2007) in Lake Banyoles (Spain), where energetic diffusive staircases develop at the upper edge of a pool of warm bottom waters, marginally stabilized by both high salinities and suspended particles. These authors report density ratios as small as $R_{\rho}=1.12$ and interfacial temperature jumps and heat fluxes comparable to our data. Observations of diffusive convection in the Weddell Sea by Robertson et al. (1995) have also found large heat fluxes of $O(1) \mathrm{W} \mathrm{m}^{-2}$ and similar temperature steps. It is interesting to note that despite the large temperature steps $\Delta \Theta$ in our observations, the relatively smaller mixed layer thicknesses $H$ result in a Rayleigh number ${ }^{1}$ distribution, $\mathrm{Ra}=g \alpha \Delta \Theta H^{3} / \nu \kappa_{T}$, that is similar to the Arctic Ocean and Lake Kivu, as well as recent numerical simulations by Hieronymus and Carpenter (2016). This means that aside from the low $R_{\rho}$ values, the diffusive convection is in a well explored region of the parameter space once appropriately scaled.

Finally, it is interesting to compare our results to the study by Kuzmina et al. (2005), who investigated generation mechanisms for different classes of intrusions found in high-resolution CTD transects in the neighboring Gotland basin, obtained after a major Baltic Sea inflow event. From a linear stability analysis of a finite-width thermohaline front, these authors identified doublediffusive interleaving, triggered by diffusive convection, as one potential generation mechanism for intrusions. Lacking observational evidence for the occurrence of diffusive convection and uncertainties in the estimation of

\footnotetext{
${ }^{1}$ In our Rayleigh number definition, we have used a $\Delta \Theta$ that corresponds to an average of the interfaces above and below the mixed layer of thickness $H$. Geometric means of Ra distributions were not found to be significantly altered by using different definitions.
} 


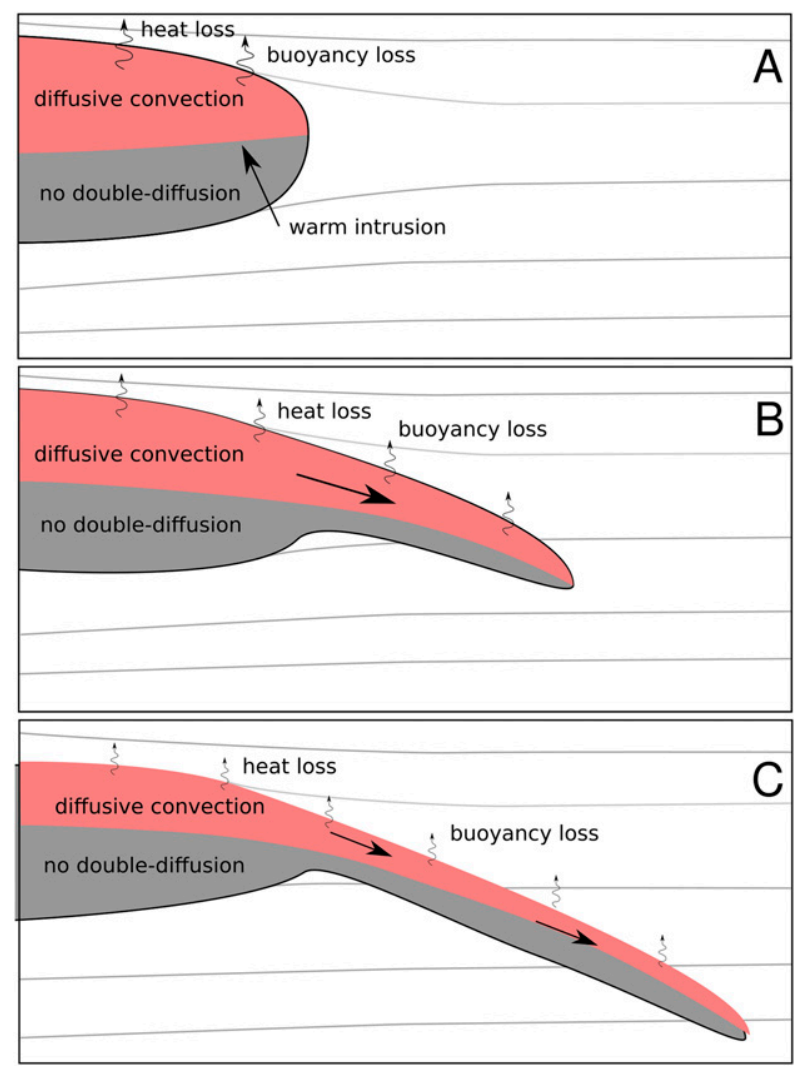

FIG. 11. Evolution of a warm intrusion with a double-diffusive staircase region at the upper flank. Thin arrows indicate the diffusive fluxes of heat (and thus buoyancy), and the thick straight arrows indicate the circulation triggered by the buoyancy loss due to diffusive mixing. Isopycnals are schematically shown as gray lines.

frontal parameters, however, complicated a conclusive comparison of theoretical predictions and observed intrusion parameters. Kuzmina et al. (2005) also pointed out that purely baroclinic processes, unrelated to the effect of double-diffusion (e.g., geostrophic adjustment of collapsing fronts and mixed fluid patches), provide another important source for the generation of intrusions.

In view of the short time scales of the intrusions in our dataset, their lacking vertical periodicity, and no indications for thermohaline fronts in our glider transects that might have generated them, double-diffusive interleaving does not seem to be a plausible generation mechanism. However, as schematically illustrated in Fig. 11, diffusive convection may still strongly modify baroclinically generated intrusions. In the example shown in Fig. 11a, this process is initiated by an interleaving gravity current with a positive temperature anomaly, that is, by a purely baroclinic mechanism. Diffusive convection developing inside the upper flank of the intruding fluid (red-shaded area in Fig. 11) induces a loss of both heat and buoyancy. The internal pressure gradient set up by the resulting density contrast with the ambient fluid induces a lateral spreading of the intrusion (Figs. 11b,c), which, because of its gradually increasing density, includes a (downward) diapycnal component. This may explain the downward sinking of the intruding waters that is evident from our glider data shown in Fig. 9. Note that salt-fingering is generally not observed at the lower edge of warm intrusions because density ratios are usually outside the parameter range for this type of double-diffusive instability.

Summarizing the above results, one of the main conclusions of our paper is that the frequently used flux parameterization of Kelley (1990) describes the directly observed interfacial fluxes within a factor of two (on the average) even in an extreme environment, characterized by rapidly varying background conditions, exceptionally large interfacial temperature jumps, and heat fluxes that might be the largest observed in the ocean. From a practical point of view, it may be relevant that data from our special instrumentation with two horizontally separated temperature microstructure sensors and a reevaluation of the direct numerical simulations by Sommer et al. (2014) suggest that the maximum heat flux inside the interface provides a robust estimate for the total interfacial heat flux. However, there is still considerable uncertainty as to the dynamics of diffusive interfaces at the extremely low density ratios observed in this study, for which no simulation results exist that we are aware of.

Finally, in a more regional context, it is important to note that our data provide the first direct and conclusive observational evidence for the importance of diffusive convection in the Baltic Sea. As the intruding and ambient waters in the Baltic Sea are of different origin, and are usually characterized by different biogeochemical properties, it is likely that a process that has the potential to mix these different water masses within a few days is relevant for the ecosystem. Work is in progress to study the impact of diffusive convection in the deeper anoxic basins of the central Baltic Sea, where intrusions with significant temperature anomalies are known to be ubiquitous.

Acknowledgments. The authors thank T. Radko and a second anonymous reviewer for their helpful and constructive comments. L.U. and P.L.H. are grateful for the support by the German Research Foundation (DFG) through Grant UM 79/5-1 to L. Umlauf. The measurements took place during the Expedition Clockwork Ocean, which was partially supported by the HelmholtzZentrum Geesthacht as part of its PACES II program. We thank captain and crew of R/V Elisabeth Mann Borgese for the excellent technical support. 


\section{APPENDIX}

\section{Computation of Interfacial Fluxes}

\section{a. Selection of staircase regions}

Staircase regions were selected manually using the highresolution thermistor data from the glider and the profiling system, respectively. This selection was based on the requirements that 1 ) the layers inside the staircase region are well-mixed as an indication for active convection, 2) that interfaces can be identified in both fast-response FP07 thermistors, and 3) that staircase regions start and end with well-mixed layers (insuring that every interface is bounded from both sides by convecting layers).

After this initial selection process, all interfaces inside a staircase region were identified based on the histogram approach described in Kelley et al. (2003). The location and magnitude of the maximum temperature gradient inside these interface regions was determined using MATLAB's "findpeaks" function, which selects the most prominent peak in a profile. Finally, exceptionally thin layers with Rayleigh numbers smaller than $\mathrm{Ra}<10^{4}$ (used as a threshold for convection) were discarded.

\section{b. Estimation of thermodynamic variables}

The fluxes computed from (3) are sensitive with respect to variations in the density ratio $R_{\rho}$, in particular for $R_{\rho} \gtrsim 1$. According to (1), this parameter depends on the differences $\Delta \Theta$ and $\Delta S_{\mathrm{A}}$ of Conservative Temperature $\Theta$ and Absolute Salinity $S_{\mathrm{A}}$ in the convective layers above and below the diffusive interfaces, and therefore special attention has to be observed when computing these quantities from the available raw data like in situ temperature $T$ and conductivity $C$.

Because of the large differences in the response times of the fast thermistors and the standard conductivity sensor, the direct computation of derived quantities like $\Theta$ and $S_{\mathrm{A}}$ may contain spikes in the vicinity of thin interfaces. We therefore used the following procedure to estimate $\Delta \Theta$ and $\Delta S_{\mathrm{A}}$ as precisely as possible from our available data. First, the averages of the in situ temperatures inside the convective layers above and below the interfaces were computed from the fast thermistor data. Because of the small response times of the thermistors, this leaves only an insignificant uncertainty of the order of the temperature fluctuations inside the convective layers (typically of order $10 \mathrm{mK}$ ). An example for a single interface with small $R_{\rho}$ is shown in Fig. A1. The uncertainty in the estimated layeraveraged conductivity $C$ is larger because the corresponding sensor has a considerably larger response time. As fast-response microconductivity data were not

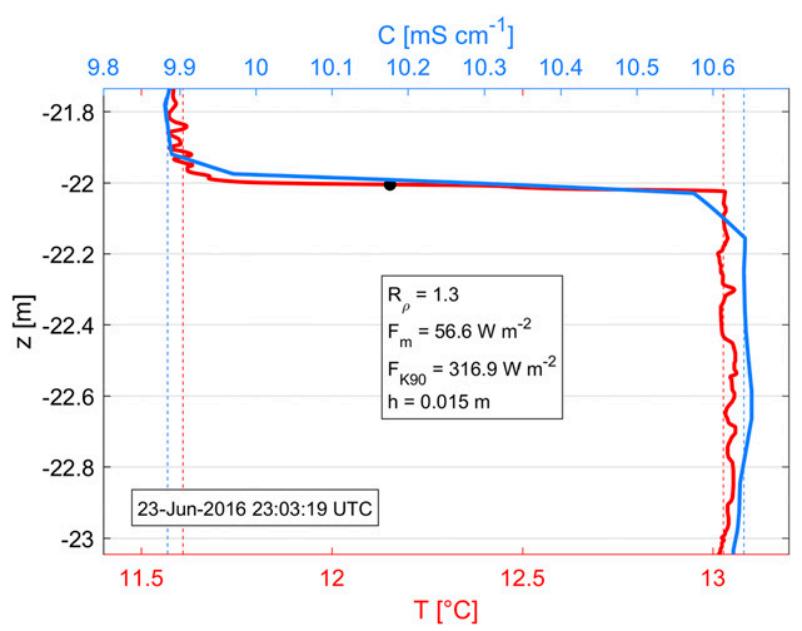

FIG. A1. Temperature from fast-response thermistor (red) and standard conductivity sensor (blue) inside a staircase region with a single interface and low $R_{\rho}$. Vertical dashed lines indicate the layer-averaged temperatures and conductivities, respectively. The black marker shows the position of the maximum temperature gradient (maximum heat flux) inside the interface. The text box summarizes some relevant interfacial properties.

available in our experiment, the uncertainty in the layeraveraged values of $C$ cannot be quantified exactly. From Fig. A1, however, an uncertainty of the order of a few percent with respect to the conductivity difference across the interface appears to be a reasonable estimate.

From these layer-averaged values of $T$ and $C$, we then computed the corresponding layer-averaged values of $\Theta$ and $S_{\mathrm{A}}$, their differences $\Delta \Theta$ and $\Delta S_{\mathrm{A}}$ across the interface, the density ratio $R_{\rho}$, and finally the interfacial heat fluxes according to (3). For the interface with the smallest density ratio in our entire dataset $\left(R_{\rho}=1.3\right.$, see Fig. A1), we estimate the following uncertainties. A 5\% uncertainty in $\Delta C$ is reflected in a $10 \%$ uncertainty in $\Delta S_{\mathrm{A}}$ and thus $R_{\rho}$. According to (3), this implies an uncertainty of approximately $30 \%$ in the heat flux. For larger $R_{\rho}$, this uncertainty quickly decays because of both the exponential character of (4) and the decreasing sensitivity of $\Delta S_{\mathrm{A}}$ with respect to $\Delta C$. In view of the uncertainties in the derivation and database of the model of Kelley (1990), this might be acceptable in most cases.

While the above approach yields reliable estimates of $R_{\rho}$ in the case of a single interface bounded by relatively thick convective layers, it turned out that individual layers in staircase regions with multiple interfaces (typically 2-4 in our observations) are often too thin to be well resolved by our conductivity sensor. In this case, we computed a single $R_{\rho}$ across the entire staircase region, assuming that this value is representative for each individual interface. This is analogous to the standard 


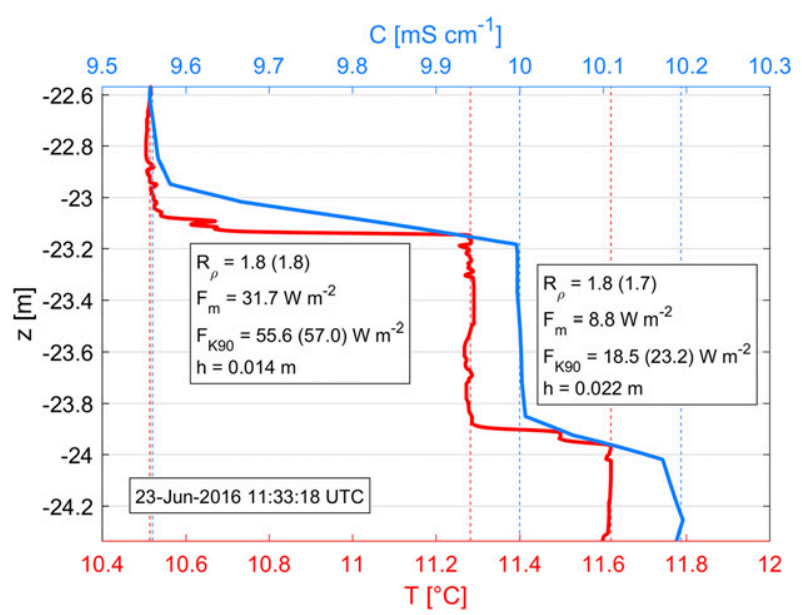

FIG. A2. As in Fig. A1 but now for a staircase region with several interfaces. Values in parentheses are computed from conductivity differences across individual interfaces.

approach (e.g., Shibley et al. 2017) of inferring $R_{\rho}$ from linear fits of temperature and salinity across a subset of the staircase region. Support for this approach comes from one of the few examples with multiple layers that were thick enough to be well resolved by the conductivity sensor (Fig. A2). This figure shows that the heat fluxes based on a single bulk value of $R_{\rho}$ for the entire staircase region only slightly deviate from the values computed for individual interfaces.

\section{c. Representative diffusive heat fluxes}

As discussed in section $3 \mathrm{c}$, we define the maximum of $F_{m}$ as the representative molecular flux through the interface. This assumption was tested using results of the direct numerical simulations described in Sommer et al. (2014). Using the simulation at $R_{\rho}=2$, we computed the vertical heat flux at each horizontal location in the domain by finding the maximum vertical temperature gradient within $5 \mathrm{~cm}$ of the central isotherm (so as not to include mixed layer structures in the analysis). These values were then compared to the net heat flux through the interface $F_{\text {net }}$, calculated using the method described in Sommer et al. (2014). The distribution of the ratio of the fluxes obtained from localized measurements of the maximum gradient, to the net flux, are shown in Fig. A3. The figure indicates that the maximum gradient method is a good indicator for the net flux, with a mean overestimate of $9 \%$, and 10 th and 90 th percentiles at $61 \%$ and $159 \%$. This suggests that the errors present in this estimate are comparable to the scatter found in the laboratory experiments that led to the Kelley parameterization, that is, a factor of approximately $40 \%$ (Kelley et al. 2003). However, it should be noted that the two-dimensional simulations have been found to

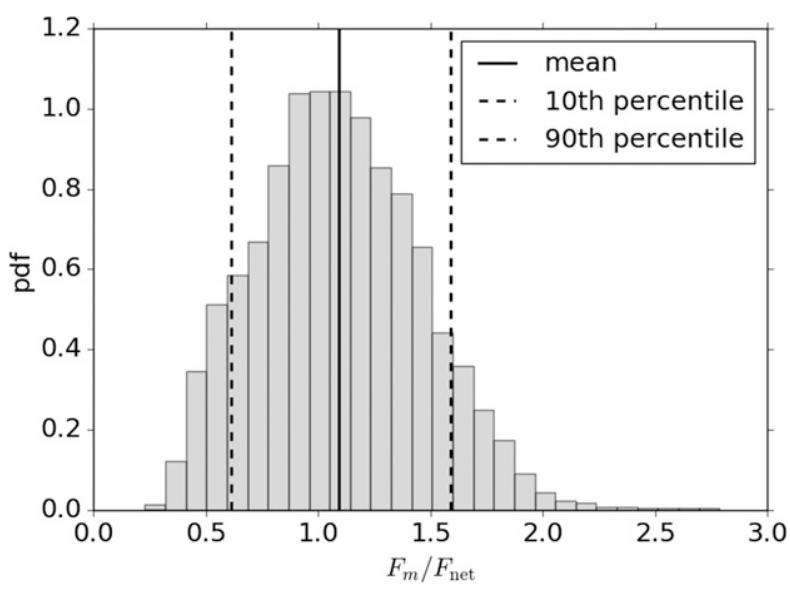

FIG. A3. Probability distribution of the ratio of fluxes $F_{m} / F_{\text {net }}$, from the direct numerical simulation with $R_{\rho}=2$ from Sommer et al. (2014).

underestimate fluxes at low $R_{\rho} \approx 2$ (Flanagan et al. 2013). This is presumably due to the onset of turbulent motions within the interface at low $R_{\rho}$ (Carpenter and Timmermans 2014). Since many interfaces with $R_{\rho}<2$ were found in the present study, the presence of these turbulent motions is expected to add additional uncertainty to the estimation of heat fluxes in these cases.

\section{REFERENCES}

Carpenter, J. R., and M.-L. Timmermans, 2014: Does rotation influence double-diffusive fluxes in polar oceans? J. Phys. Oceanogr., 44, 289-296, https://doi.org/10.1175/JPO-D-13-098.1.

_ T. Sommer, and A. Wüest, 2012: Simulations of a doublediffusive interface in the diffusive convection regime. J. Fluid Mech., 711, 411-436, https://doi.org/10.1017/jfm.2012.399.

Feistel, R., G. Nausch, and N. Wasmund, Eds., 2008: State and Evolution of the Baltic Sea, 1952-2005: A Detailed 50-Year Survey of Meteorology and Climate, Physics, Chemistry, Biology, and Marine Environment. Wiley-Interscience, 703 pp.

Flanagan, J., A. Lefler, and T. Radko, 2013: Heat transport through diffusive interfaces. Geophys. Res. Lett., 40, 2466-2470, https:// doi.org/10.1002/grl.50440.

Garau, B., S. Ruiz, W. G. Zhang, A. Pascual, E. Heslop, J. Kerfoot, and J. Tintoré, 2011: Thermal lag correction on Slocum CTD glider data. J. Atmos. Oceanic Technol., 28, 1065-1071, https:// doi.org/10.1175/JTECH-D-10-05030.1.

Guthrie, J. D., I. Fer, and J. Morison, 2015: Observational validation of the diffusive convection flux laws in the Amundsen Basin, Arctic Ocean. J. Geophys. Res. Oceans, 120, 7880-7896, https://doi.org/10.1002/2015JC010884.

— — - and — 2017: Thermohaline staircases in the Amundsen Basin: Possible disruption by shear and mixing. J. Geophys. Res. Oceans, 122, 7767-7782, https://doi.org/ 10.1002/2017JC012993.

Hieronymus, M., and J. Carpenter, 2016: Energy and variance budgets of a diffusive staircase with implications for heat flux scaling. J. Phys. Oceanogr., 46, 2553-2569, https://doi.org/ 10.1175/JPO-D-15-0155.1. 
Holtermann, P., L. Umlauf, T. Tanhua, O. Schmale, G. Rehder, and J. Waniek, 2012: The Baltic Sea Tracer Release Experiment. 1. Mixing rates. J. Geophys. Res., 117, C01021, https:// doi.org/10.1029/2011JC007439.

_ , R. Prien, V. Mohrholz, and L. Umlauf, 2017: Deep-water dynamics and mixing processes during a major inflow event in the central Baltic Sea. J. Geophys. Res. Oceans, 122, 66486667, https://doi.org/10.1002/2017JC013050.

IOC, SCOR, and IAPSO, 2010: The International Thermodynamic Equation of Seawater-2010: Calculation and use of thermodynamic properties. Intergovernmental Oceanographic Commission, Manuals and Guides 56, UNESCO, 196 pp., http:// www.teos-10.org/pubs/TEOS-10_Manual.pdf.

Kelley, D. E., 1990: Fluxes through diffusive staircases: A new formulation. J. Geophys. Res., 95, 3365-3371, https://doi.org/ 10.1029/JC095iC03p03365.

— H. J. S. Fernando, A. E. Gargett, J. Tanny, and E. Özsoy, 2003: The diffusive regime of double-diffusive convection. Prog. Oceanogr., 56, 461-481, https://doi.org/10.1016/S00796611(03)00026-0.

Kuzmina, N., B. Rudels, T. Stipa, and V. Zhurbas, 2005: The structure and driving mechanisms of the Baltic intrusions. J. Phys. Oceanogr., 35, 1120-1137, https://doi.org/10.1175/ JPO2749.1.

Lappe, C., and L. Umlauf, 2016: Efficient boundary mixing due to near-inertial waves in a nontidal basin: Observations from the Baltic Sea. J. Geophys. Res. Oceans, 121, 8287-8304, https:// doi.org/10.1002/2016JC011985.

Merckelbach, L., D. Smeed, and G. Griffiths, 2010: Vertical velocities from underwater gliders. J. Atmos. Oceanic Technol., 27, 547-563, https://doi.org/10.1175/2009JTECHO710.1.

Prien, R. D., and D. E. Schulz-Bull, 2016: Technical note: GODESS-A profiling mooring in the Gotland Basin. Ocean Sci., 12, 899-907, https://doi.org/10.5194/os-12-899-2016.

Radko, T., 2003: A mechanism for layer formation in a doublediffusive fluid. J. Fluid Mech., 497, 365-380, https://doi.org/ 10.1017/S0022112003006785.

_ 2013: Double-Diffusive Convection. Cambridge University Press, 342 pp.

_ J. Flanagan, S. Stellmach, and M.-L. Timmermans, 2014: Double-diffusive recipes. Part II: layer-merging events. J. Phys. Oceanogr., 44, 1285-1305, https://doi.org/10.1175/JPO-D-13-0156.1.

Rippeth, T., B. Lincoln, Y.-D. Lenn, J. M. Green, A. Sundfjord, and S. Bacon, 2015: Tide-mediated warming of Arctic halocline by Atlantic heat fluxes over rough topography. Nat. Geosci., 8, 191-194, https://doi.org/10.1038/ngeo2350.

Robertson, R., L. Padman, and M. Levine, 1995: Fine structure, microstructure, and vertical mixing processes in the upper ocean in the western Weddell Sea. J. Geophys. Res., 100 18 517-18 535, https://doi.org/10.1029/95JC01742.
Sánchez, X., and E. Roget, 2007: Microstructure measurements and heat flux calculations of a triple-diffusive process in a lake within the diffusive layer convection regime. J. Geophys. Res., 112, C02012, https://doi.org/10.1029/2006JC003750.

Scheifele, B., R. Pawlowicz, T. Sommer, and A. Wüest, 2014: Double diffusion in saline Powell Lake, British Columbia. J. Phys. Oceanogr., 44, 2893-2908, https://doi.org/10.1175/ JPO-D-14-0070.1.

Schmid, M., M. Busbridge, and A. Wüest, 2010: Double-diffusive convection in Lake Kivu. Limnol. Oceanogr., 55, 225-238, https://doi.org/10.4319/lo.2010.55.1.0225.

Sharqawy, M. H., J. H. Lienhard, and S. M. Zubair, 2010: Thermophysical properties of seawater: A review of existing correlations and data. Desalin. Water Treat., 16, 354-380, https:// doi.org/10.5004/dwt.2010.1079.

Shibley, N. C., M.-L. Timmermans, J. R. Carpenter, and J. M. Toole, 2017: Spatial variability of the Arctic Ocean's doublediffusive staircase. J. Geophys. Res. Oceans, 122, 980-994, https://doi.org/10.1002/2016JC012419.

Sirevaag, A., and I. Fer, 2012: Vertical heat transfer in the Arctic Ocean: The role of double-diffusive mixing. J. Geophys. Res., 117, C07010, https://doi.org/10.1029/2012JC007910.

Sommer, T., J. Carpenter, M. Schmid, R. Lueck, M. Schurter, and A. Wüest, 2013a: Interface structure and flux laws in a natural double-diffusive layering. J. Geophys. Res. Oceans, 118, 60926106, https://doi.org/10.1002/2013JC009166.

$,-,-\longrightarrow,-$, and A. Wüest, 2013b: Revisiting microstructure sensor responses with implications for doublediffusive fluxes. J. Atmos. Oceanic Technol., 30, 1907-1923, https://doi.org/10.1175/JTECH-D-12-00272.1.

,$- \ldots$, and A. Wüest, 2014: Double-diffusive interfaces in Lake Kivu reproduced by direct numerical simulations. Geophys. Res. Lett., 41, 5114-5121, https://doi.org/10.1002/ 2014 GL060716.

Timmermans, M.-L., C. Garrett, and E. Carmack, 2003: The thermohaline structure and evolution of the deep waters in the Canada Basin, Arctic Ocean. Deep-Sea Res. I, 50, 1305-1321, https://doi.org/10.1016/S0967-0637(03)00125-0.

_ J. M. Toole, R. Krishfield, and P. Winsor, 2008: Ice-tethered profiler observations of the double-diffusive staircase in the Canada Basin thermocline. J. Geophys. Res., 113, C00A02, https://doi.org/10.1029/2008JC004829.

van der Lee, E. M., and L. Umlauf, 2011: Internal wave mixing in the Baltic Sea: Near-inertial waves in the absence of tides. J. Geophys. Res., 116, C10016, https://doi.org/10.1029/ 2011JC007072.

Wieczorek, G., E. Hagen, and L. Umlauf, 2008: Eastern Gotland Basin case study of thermal variability in the wake of deep water intrusions. J. Mar. Res., 74 (Suppl.), S65-S97, https:// doi.org/10.1016/j.jmarsys.2008.07.008. 